Revista Brasileira de Agricultura Irrigada v.13, nº.2, p. 3314 - 3326, 2019

ISSN 1982-7679 (On-line)

Fortaleza, CE, INOVAGRI - http://www.inovagri.org.br

DOI: $10.7127 /$ rbai.v13n2001030

Protocolo 1030.19 - 17/10/2018 Aprovado em 13/05/2019

\title{
PRECIPITAÇÃO MENSAL PROVÁVEL NO NOROESTE DO PARANÁ
}

\author{
Daniela D’Orazio Bortoluzzi ${ }^{1}$, Giuliani do Prado $^{2}$, Anderson Takashi Hara ${ }^{3}$, Ana Claudia Sossai \\ Souza $^{4}$
}

\section{RESUMO}

O trabalho foi conduzido na Universidade Estadual de Maringá, em Cidade Gaúcha, Paraná, e objetivou avaliar a estrutura e o padrão espacial da precipitação mensal provável, no Noroeste do Estado do Paraná. Quarenta e três séries históricas de precipitações mensais das microrregiões de Cianorte, Paranavaí e Umuarama foram utilizadas. Os dados de precipitação mensal com $75 \%$ de probabilidade de ocorrência foram determinados a partir da função de distribuição de probabilidade Gama. Técnicas geoestatísticas foram empregadas para o estudo da variabilidade e do padrão espacial das precipitações, bem como, para a construção de mapas de contorno para os diferentes meses do ano. Os resultados da pesquisa evidenciam que: i) a variável em estudo apresentou estrutura de dependência espacial com alcance de $116 \mathrm{~km}$; ii) o período com maior índice pluviométrico tem início em setembro e prolonga-se até março; iii) a menor precipitação ocorre no período de abril a agosto e; iv) nos meses de inverno (junho, julho e agosto), a precipitação provável é menor que $60 \mathrm{~mm}$. De acordo com a análise de estabilidade temporal, verificou-se que, para determinação de valores médios de precipitação provável na região Noroeste do Paraná, os dados da estação meteorológica de Tapejara, localizada na microrregião de Cianorte, tem maior representatividade.

Palavras-chave: geoestatística, variabilidade espacial, dependência espacial

\section{PROBABLE MONTHLY RAINFALL IN THE NORTHWEST OF PARANÁ STATE, BRAZIL}

\footnotetext{
ABSTRACT

The work was carried out at the Universidade Estadual de Maringá, in Cidade Gaúcha city, Paraná State, Brazil and aimed to evaluate the structure and spatial pattern of probable monthly rainfall for

${ }^{1}$ Engenheira Agrícola, Doutoranda no Programa de Pós-graduação em Agronomia da Universidade Estadual de Maringá, Maringá-PR, CEP: 87.020-900, e-mail: bortoluzzidd@gmail.com.

${ }^{2}$ Engenheiro Agrônomo, Professor Associado A do Departamento de Engenharia Agrícola da Universidade Estadual de Maringá, Cidade Gaúcha-PR, CEP: 87.820-000, e-mail: gprado@uem.br.

${ }^{3}$ Engenheiro Agrônomo, Doutor em Agronomia, Universidade Estadual de Maringá, Maringá-PR, CEP: 87.020-900, e-mail: haratakashi1987@gmail.com.

${ }^{4}$ Engenheira Agrônoma, Doutoranda no Programa de Pós-graduação em Agronomia da Universidade Estadual de Maringá, Maringá-PR, CEP: 87.020-900, e-mail: ana_sossai87@ hotmail.com.
} 
the northwest of Paraná State, Brazil. Forty-three historical data series of monthly rainfall from the Cianorte, Paranavaí, and Umuarama micro-regions were used. Monthly rainfall data with a $75 \%$ probability of occurrence were determined from the Gamma probability distribution function. Geostatistical techniques were employed for the study of variability and spatial pattern of rainfalls as well as to draw contour maps for the different months of the year. The research outcomes showed that: i) the variable studied presented a spatial dependence structure with a range of $116 \mathrm{~km}$; ii) the period with the highest amount of rainfall starts in September and lasts until March; iii) the lowest amount of rainfall occurs between April and August and; iv) in the winter months (June, July, and August), the probable rainfall is less than $60 \mathrm{~mm}$. According to the temporal stability analysis, data from the weather station of Tapejara, in the Cianorte micro-region, are more representative to compute the mean values of probable rainfall in the Northwest region of Paraná state.

Keywords: geostatistics, spatial variability, spatial dependence

\section{INTRODUÇÃO}

A disponibilidade hídrica no solo de uma região é essencial no desenvolvimento de atividades de preparo e manejo do solo e para a adoção de um sistema irrigado de cultivo visando o sucesso na produtividade agrícola (DANFÁ et al., 2011). Conforme Longo et al. (2006), na agricultura irrigada, a precipitação pluviométrica é parâmetro fundamental para o manejo e dimensionamento de sistemas de irrigação.

Devido à relevância dos dados pluviométricos, há o esforço de quantificar e prever sua ocorrência nos mais variados locais (COAN et al., 2014). Segundo Bernardo et al. (2006), a probabilidade de ocorrência de chuvas, que representa a precipitação igual ou superior ao valor estimado para determinado período, tem papel importante no planejamento de sistemas de irrigação, reduzindo os custos de aquisição e o risco de escassez de água. Desse modo, para garantir um valor mínimo de lâmina de chuva, Lima et al. (2016) têm sugerido a precipitação com $75 \%$ de probabilidade de ocorrência como adequada para fins agrícolas.

Os dados de precipitação pluviométrica apresentam grande variabilidade espacial e temporal (COAN et al., 2014; FRAZIER et al., 2016; JAVARI, 2017), tornando-se fundamental a caracterização do seu padrão local e suas variações (ALMEIDA et al, 2011). Wanderley et al. (2013) relatam a relevância da geoestatística para o estudo da distribuição da precipitação, principalmente, na utilização do método de interpolação por krigagem para gerar informações espaciais. Conforme Mello et al. (2012) e Andrade et al. (2018), estudos aplicando o interpolador geoestatístico de krigagem para dados de precipitações pluviométrica vem revelando bons resultados.

Para suprir a carência de séries históricas de precipitação pluviométrica em regiões que não apresentam estações meteorológicas, o emprego da geoestatística torna-se uma ferramenta essencial na elaboração de mapas de precipitação. Dessa forma, o trabalho teve por objetivos: i) determinar a variabilidade e o padrão espacial da precipitação provável mensal a $75 \%$ de probabilidade de ocorrência; ii) elaborar mapas da precipitação pluvial mensal e; iii) identificar, entre as estações estudadas, a existência da estabilidade temporal de uma posição que possa estimar a condição média da variável em estudo.

\section{MATERIAL E MÉTODOS}

O trabalho foi desenvolvido no Departamento de Engenharia Agrícola da Universidade Estadual de Maringá, em Cidade Gaúcha-PR. Para tanto, séries históricas de totais mensais de precipitações de cidades localizadas na região Noroeste do estado do Paraná (Figura 1) foram obtidas junto ao portal HidroWeb do Sistema Nacional de Informações sobre Recursos Hídricos (SNIRH) da Agência Nacional de Águas (ANA, 2018). 


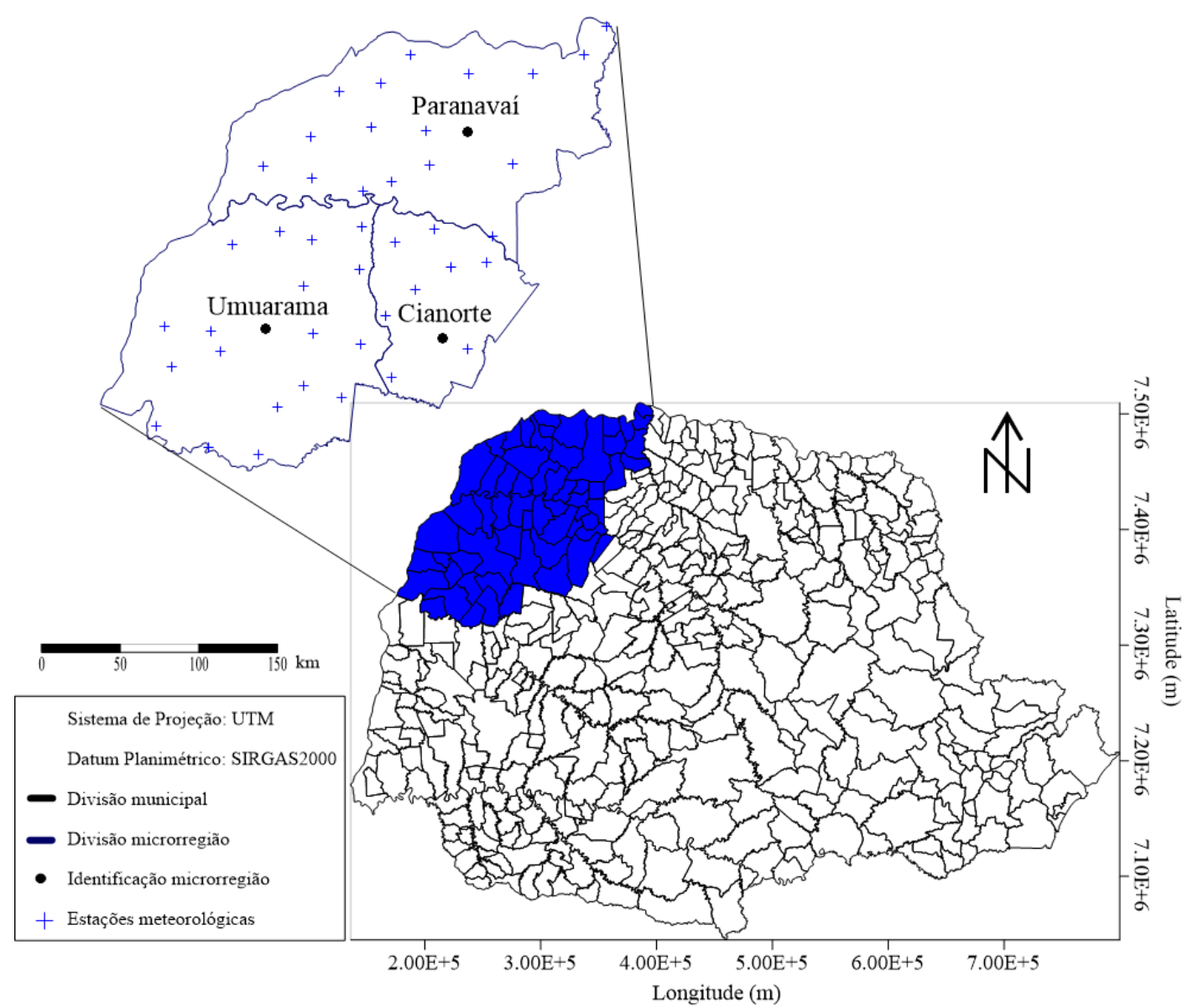

Figura 1. Microrregiões do Noroeste do Paraná e distribuição espacial das estações meteorológicas utilizadas neste estudo.

A região noroeste do Paraná é constituída pelas microrregiões de Cianorte, Paranavaí e Umuarama. O clima da região, segundo Köppen, é classificado como Subtropical Úmido (mesotérmico) e encontrase no domínio do bioma Floresta Estacional Semidecidual (SOUZA, 2006). Para essas três microrregiões foram obtidas, respectivamente,
15, 38 e 32 séries históricas de precipitações totais mensais.

Entretanto, devido a cidades que apresentavam mais de uma série histórica e, principalmente, devido a falhas de coleta nos dados de precipitação foram empregadas 43 séries históricas para as três microrregiões (Tabela 1). 
Tabela 1. Séries históricas das microrregiões (M.R.) de Cianorte (C), Paranavaí (P) e Umuarama (U) obtidas junto ao HidroWeb da ANA.

\begin{tabular}{cccc|cccc}
\hline $\begin{array}{c}\text { Código } \\
\text { Estação }\end{array}$ & M.R. & Cidade & Anos & $\begin{array}{c}\text { Código } \\
\text { Estação }\end{array}$ & M.R. & Cidade & Anos \\
\hline 2352031 & $\mathrm{C}$ & Cianorte & 39 & 2352036 & $\mathrm{P}$ & São Carlos do Ivaí & 32 \\
2352046 & $\mathrm{C}$ & Cidade Gaúcha & 39 & 2253008 & $\mathrm{P}$ & São Pedro do Paraná & 40 \\
2352047 & $\mathrm{C}$ & Guaporema & 32 & 2252022 & $\mathrm{P}$ & Terra Rica & 39 \\
2352044 & $\mathrm{C}$ & Indianópolis & 34 & 2453008 & $\mathrm{U}$ & Alto Piquiri & 47 \\
2352045 & $\mathrm{C}$ & Japurá & 34 & 2353003 & $\mathrm{U}$ & Altonia & 42 \\
2352043 & $\mathrm{C}$ & Rondon & 34 & 2453050 & $\mathrm{U}$ & Brasilandia do Sul & 38 \\
2352042 & $\mathrm{C}$ & Tapejara & 36 & 2353004 & $\mathrm{U}$ & Cruzeiro do Oeste & 41 \\
2352026 & $\mathrm{C}$ & Tuneiras do Oeste & 35 & 2353033 & $\mathrm{U}$ & Douradina & 38 \\
2352051 & $\mathrm{P}$ & Amaporã & 38 & 2453052 & $\mathrm{U}$ & Francisco Alves & 36 \\
2252015 & $\mathrm{P}$ & Diamante do Norte & 39 & 2353031 & $\mathrm{U}$ & Icaraíma & 37 \\
2252025 & $\mathrm{P}$ & Guairaçá & 31 & 2453000 & $\mathrm{U}$ & Iporã & 34 \\
2252013 & $\mathrm{P}$ & Jardim Olinda & 41 & 2353032 & $\mathrm{U}$ & Ivaté & 30 \\
2253013 & $\mathrm{P}$ & Loanda & 38 & 2353028 & $\mathrm{U}$ & Maria Helena & 38 \\
2252020 & $\mathrm{P}$ & Nova Londrina & 33 & 2353006 & $\mathrm{U}$ & Mariluz & 45 \\
2252019 & $\mathrm{P}$ & Paranapoema & 36 & 2353029 & $\mathrm{U}$ & Nova Olímpia & 36 \\
2352017 & $\mathrm{P}$ & Paranavaí & 42 & 2353014 & $\mathrm{U}$ & Perobal & 25 \\
2352048 & $\mathrm{P}$ & Planaltina do Paraná & 39 & 2353016 & $\mathrm{U}$ & Pérola & 35 \\
2353010 & $\mathrm{P}$ & Querência do Norte & 38 & 2353019 & $\mathrm{U}$ & São J. do Patrocínio & 36 \\
2253011 & $\mathrm{P}$ & Santa C. do M. Castelo & 36 & 2353034 & $\mathrm{U}$ & Tapira & 37 \\
2353038 & $\mathrm{P}$ & Santa Isabel do Ivaí & 37 & 2353008 & $\mathrm{U}$ & Umuarama & 43 \\
2353041 & $\mathrm{P}$ & Santa Mônica & 40 & 2353020 & $\mathrm{U}$ & Xambre & 37 \\
2252024 & $\mathrm{P}$ & Santo Antônio do Caiuá & 40 & & & & \\
\hline
\end{tabular}

Os dados de precipitações totais mensais nas séries históricas de cada mês foram organizados em ordem decrescente e numerados a partir do maior valor. A esses valores, através da equação de Kimball

$$
\mathrm{F}=\frac{\mathrm{m}}{\mathrm{N}+1}
$$

Em que:

F - frequência de excedência observada, decimal;

m - número de ordem, decimal; e,

$\mathrm{N}$ - número de elementos na amostra, decimal.
(VILLELA; MATTOS, 1975), foi calculada a frequência com que o valor de precipitação possa ser igualado ou superado, pelo menos uma vez num período " $\mathrm{N}$ " de anos, por:

$$
\begin{gathered}
\hat{\mathrm{F}}=\frac{1}{\beta^{\alpha} \cdot \Gamma(\alpha)} \cdot \mathrm{x}^{\alpha-1} \cdot \mathrm{e}^{-\frac{\mathrm{x}}{\beta}} \\
\beta=\frac{\mathrm{s}^{2}}{\overline{\mathrm{x}}} \\
\alpha=\frac{\bar{x}^{2}}{\mathrm{~s}^{2}}
\end{gathered}
$$

Com base na média e no desvio padrão amostral, nas séries históricas e para cada mês, foi estimada a frequência de excedência (Eqs. 2, 3 e 4), a partir da função densidade de probabilidade Gama (TUCCI e SILVEIRA, 2009.) 
Em que:

$\hat{\mathrm{F}}$ - frequência de excedência estimada através da função Gama, decimal;

x - precipitação observada, mm;

$\overline{\mathrm{x}}$ - média amostral das precipitações observadas, $\mathrm{mm}$; e,

$\mathrm{s}^{2}$ - desvio padrão amostral das precipitações observadas, mm.

A aderência dos valores de frequência estimados através da função de distribuição de probabilidade Gama aos valores de frequência observadas, calculados pela Equação 1, foi verificada através do teste de KolmogorovSmirnov a 5\% de probabilidade (FREITAS, et al., 2001).

O valor tabelado do teste é considerado estatisticamente nulo, denotando que, se a máxima diferença entre os valores observados e estimados $(\operatorname{Max}|\Delta \mathrm{F}|)$ for menor ou igual a esse valor $\left(\operatorname{Max}|\Delta \mathrm{F}|_{\text {calculado }} \leq|\Delta \mathrm{F}|_{\text {tabelado }}\right)$, as duas amostras são iguais.
Conforme Bernardo et al. (2006), precipitação provável é a quantidade mínima de chuva com determinada probabilidade de ocorrência. Para irrigação e planejamento agrícola pode-se trabalhar com a probabilidade de $75 \%$, que representa a precipitação mínima que pode ser esperada a cada quatro anos. Desta forma, calculou-se a precipitação provável mensal $(\mathrm{P} \geq 75 \%)$ através da distribuição Gama para as três microrregiões do Noroeste do estado do Paraná.

Após uma minuciosa análise utilizando ferramentas de estatística descritiva e exploratória, foi confirmada que o processo estocástico da variável aleatória em estudo atende a hipótese de estacionaridade no mínimo intrínseca. Portanto, buscou-se descrever a estrutura de dependência espacial por meio de análises variográficas que tiveram por base a estimativa da função de semivariância dada pela Eq. 5 .

$$
\gamma(\mathrm{h})=\frac{1}{2 \mathrm{~N}(\mathrm{~h})} \sum_{\mathrm{i}=1}^{\mathrm{N}(\mathrm{h})}\left[\mathrm{Z}\left(\mathrm{s}_{\mathrm{i}}\right)-\mathrm{Z}\left(\mathrm{s}_{\mathrm{i}}+\mathrm{h}\right)\right]^{2}
$$

Em que:

$\gamma(\mathrm{h})$ - semivariância estimada;

$\mathrm{N}(\mathrm{h})$ - número de pares de valores da variável $\mathrm{Z}$, medidos em pontos separados pela distância $\mathrm{h} ; \mathrm{e}$,

$\mathrm{Z}\left(\mathrm{S}_{\mathrm{i}}\right)$ - valor da variável $\mathrm{Z}$ na localização $\mathrm{S}_{\mathrm{i}}$ no espaço. $\mathrm{Na}$ geração dos variogramas, foi realizada a remoção de outliers para maior

$$
\begin{aligned}
& \mathrm{LI}=\mathrm{QI}-1,5 \cdot \mathrm{AI} \\
& \mathrm{LS}=\mathrm{QS}+1,5 \cdot \mathrm{AI}
\end{aligned}
$$

Em que:

LI e LS - limites, respectivamente, superiores e inferiores na identificação de outliers, mm; QI e QS - quartis inferior e superior, respectivamente, $\mathrm{mm}$; $\mathrm{e}$,

AI - amplitude interquartílica, mm.

A estrutura de um semivariograma é composta pelos parâmetros: i) efeito pepita (C0), que revela a descontinuidade na origem confiabilidade, sendo a necessidade confirmada pela distribuição dos valores da relação gráfica $\mathrm{Z}(\mathrm{x}+\mathrm{h}) / \mathrm{Z}(\mathrm{x})$ fornecidas pelo h-scatterplot do software $\quad$ VARIOWIN. $\mathrm{Na}$ identificação de outliers, também foi adotado os limites inferior e superior fixados pelas Eqs. 6 e 7 .

do semivariograma; ii) alcance (A), que representa a distância limite da dependência espacial e; iii) contribuição (C1), que é a diferença entre o patamar e o efeito pepita. Com objetivo de comparar os semivariogramas experimentais, estes foram escalonados conforme metodologia proposta por Vieira et al. (1991) (Eq. 8). 


$$
\gamma(\mathrm{h}) *=\frac{\gamma(\mathrm{h})}{\operatorname{Var}(\mathrm{Z})}
$$

Em que:

$\gamma(\mathrm{h})^{*}$ - semivariância escalonada;

$\gamma(\mathrm{h})$ - semivariância; e,

$\operatorname{Var}(\mathrm{Z})$ - variância amostral das observações.

A representação espacial dos dados de precipitação provável, para os doze meses do ano, foi feita através de mapas de isolinhas, empregando a técnica de interpolação por krigagem com auxílio do aplicativo computacional SURFER. Esse programa foi alimentado com dados gerados através do

$$
\delta_{\mathrm{ij}}=\frac{\left(\mathrm{p}_{\mathrm{ij}}-\overline{\mathrm{p}_{\mathrm{j}}}\right)}{\overline{\mathrm{p}_{\mathrm{j}}}}
$$

Em que:

$\delta_{\mathrm{ij}}$ - diferença relativa da posição i no momento j;

$\mathrm{p}_{\mathrm{ij}}$ - precipitação provável mensal $(\mathrm{P} \geq 75 \%)$ da posição i no momento $\mathrm{j}, \mathrm{mm}$; e,

$\overline{p_{j}}$ - precipitação média $(P \geq 75 \%)$ de todas as posições no espaço, no momento $\mathrm{j}$, $\mathrm{mm}$.

Para cada posição i no espaço, em cada tempo $\mathrm{j}$, foram calculadas as diferenças relativas e a média dos valores de diferença relativa (DRM) considerando os diversos momentos j (GONÇALVES et al., 1999). A posição que apresenta um valor de DRM igual a zero representa a condição média de um domínio experimental de uma dada variável.

\section{RESULTADOS E DISCUSSÃO}

Os valores de precipitações totais mensais, para os diferentes meses do ano, obtidos nas séries históricas de estações pluviométricas da região noroeste do Paraná modelo ajustado ao semivariograma médio, que teve os coeficientes do modelo validados pelo teste "t" ao nível de probabilidade de 5\% $(\mathrm{p}<0,05)$ através do programa estatístico $\mathrm{R}$.

Com o intuito de identificar a estação meteorológica que possa representar a condição média da região, foi calculado, utilizando os valores da precipitação provável mensal $\quad(P \geq 75 \%), \quad$ a diferença relativa proposta por Vachaud et al. (1985), dada pela Eq. 9.

são apresentados na Figura 2. Existe uma grande variação temporal nos dados de precipitação observados e os $50 \%$ dos valores mais prováveis encontram-se dentro do intervalo vertical de cada caixa (boxplot). Conforme Araújo et al. (2001), essas variações temporais nos dados de precipitação geram incertezas e o emprego de estudos probabilísticos é essencial na tomada de decisão para o planejamento agrícola e na adoção de sistemas de irrigação.

A sazonalidade anual nos dados de precipitação evidencia um decréscimo na quantidade de precipitação ao longo do ano (Figura 2). Essa redução tem início no mês de janeiro, estende-se até agosto, que é o mês mais seco, e partir de setembro, os índices pluviométricos na região voltam a aumentar até o mês de dezembro. Segundo Fritzsons et al. (2011) e Santos et al. (2017), a região noroeste do Paraná apresenta a menor precipitação do Estado, o clima é mais seco e há ocorrência de estiagens no inverno. 


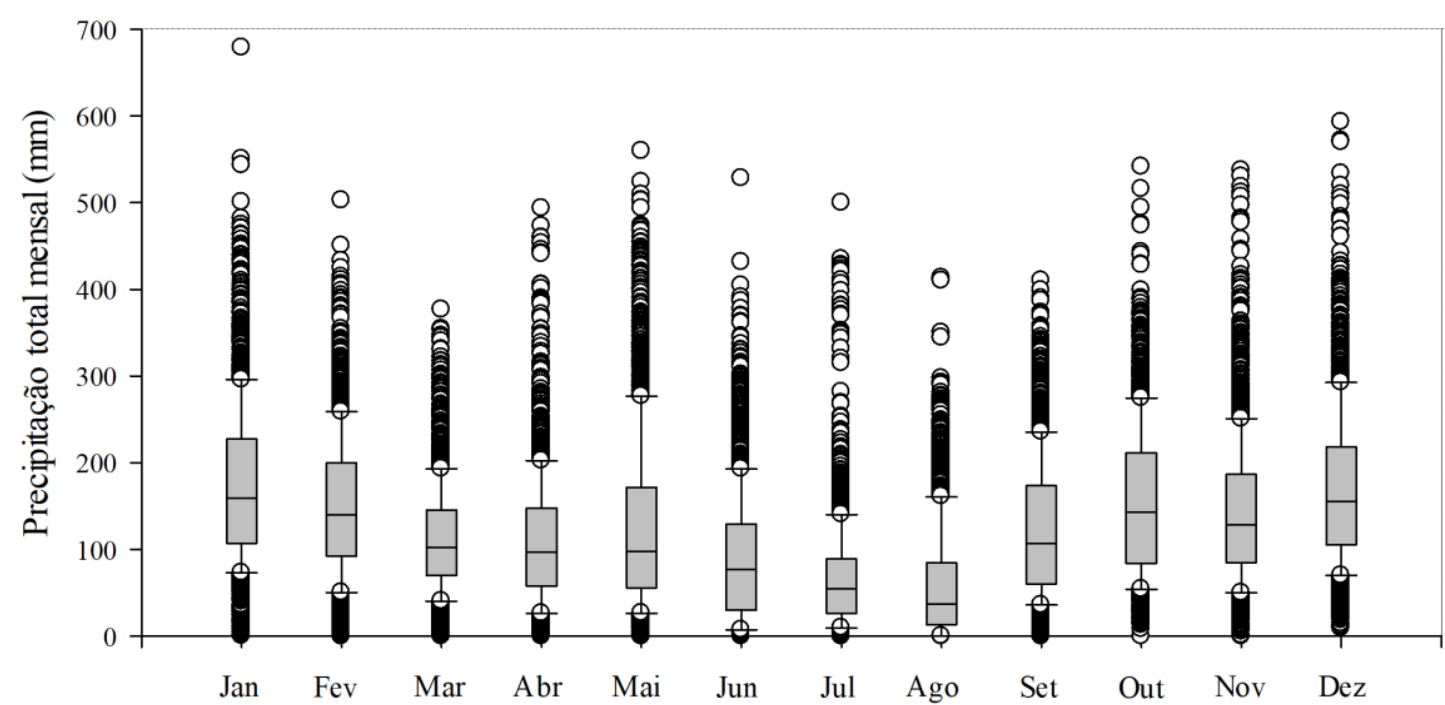

Figura 2. Distribuição dos valores de precipitações totais mensais observadas nas séries históricas para a região Noroeste do Paraná.

De acordo com a Figura 2, na região noroeste do Paraná, os meses compreendidos entre outubro a janeiro apresentam maiores índices pluviométricos com $50 \%$ dos valores mais prováveis compreendidos num intervalo de 90 a $230 \mathrm{~mm}$, representando, respectivamente, 6,0 e $15,4 \%$ da média histórica do total anual precipitado.

Todavia, nos meses de junho, julho e agosto, meses de inverno, esses índices de chuvas são menores e estão compreendidos entre 10 a $120 \mathrm{~mm}$, ou seja, 0,7 e $8,0 \%$ da média histórica do total anual precipitado, respectivamente.

Na Figura 2, também se observa, a ocorrência de valores atípicos de precipitação (outliers), com incidência de lâminas de chuvas muito acima ou muito baixo dos valores prováveis de precipitação (Figura 2).

Esses dados também têm grande relevância para o dimensionamento de obras hidráulicas (valores máximos) ou no planejamento e gestão de recursos hídricos em bacias hidrográficas (valores mínimos) para concessão de outorga com vistas à irrigação (TUCCI e SILVEIRA, 2009).

Ao aplicar o teste de aderência de Kolmogorov-Smirnov, ao nível de 5\% de significância, observou-se que as diferenças máximas (Figura 3) entre os valores de frequências observadas e estimadas pela função Gama se devem ao acaso. Dessa maneira, essa função de probabilidade foi empregada para estimar os valores de precipitações prováveis mensais $(\mathrm{P} \geq 75 \%)$ para todas as séries históricas das cidades do noroeste do Paraná.

Existem diversos estudos que apontam que a distribuição Gama é o modelo probabilístico mais utilizado para a estimativa da precipitação provável em diferentes locais e níveis de probabilidade (BAÚ et al., 2006; PASSOS et al., 2017; SANTIAGO et al., 2017; PASSOS e MENDES 2018). 


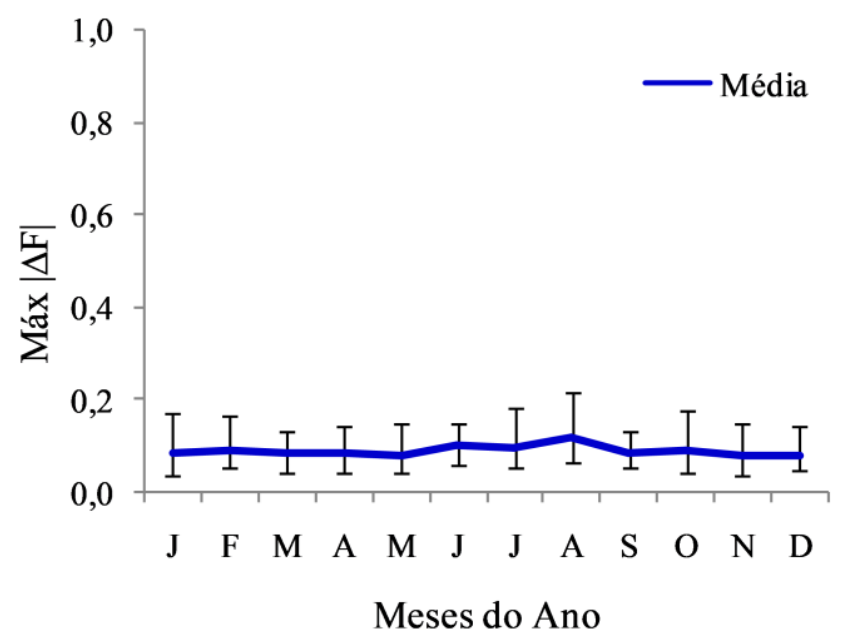

Figura 3. Máxima diferença $(\operatorname{Máx}|\Delta \mathrm{F}|)$ entre os valores de frequências observadas e estimadas pela função de distribuição de probabilidade Gama para os diferentes meses do ano. Barras verticais representam o intervalo entre valores máximos e mínimos.

Para avaliação da dependência espacial da precipitação provável mensal, foram construídos semivariogramas experimentais. Pode-se observar na Figura 4 que, os meses de janeiro, fevereiro, abril, maio, julho, setembro e dezembro apresentaram estrutura de dependência espacial, possibilitando o ajuste de um único modelo ao conjunto de valores de semivariância (GONÇALVES et al., 2010). O modelo esférico foi adotado por apresentar melhor ajuste aos dados de precipitação (BAÚ et al., 2016; LIMA et al., 2016). Constatou-se que os meses que apresentaram estrutura de dependência espacial ocorreram de modo intercalado, evidenciando que a dependência espacial é persistente no tempo, portanto o modelo apresentado na Figura 4 expressa um modelo médio dessa estrutura. Para os meses de março, junho, agosto, outubro e novembro não foi possível a identificação de estrutura de dependência espacial, provavelmente pela combinação do erro estocástico não estruturado com a intensidade amostral adotada no trabalho, não possibilitando um adequado funcionamento da função de semivariância.

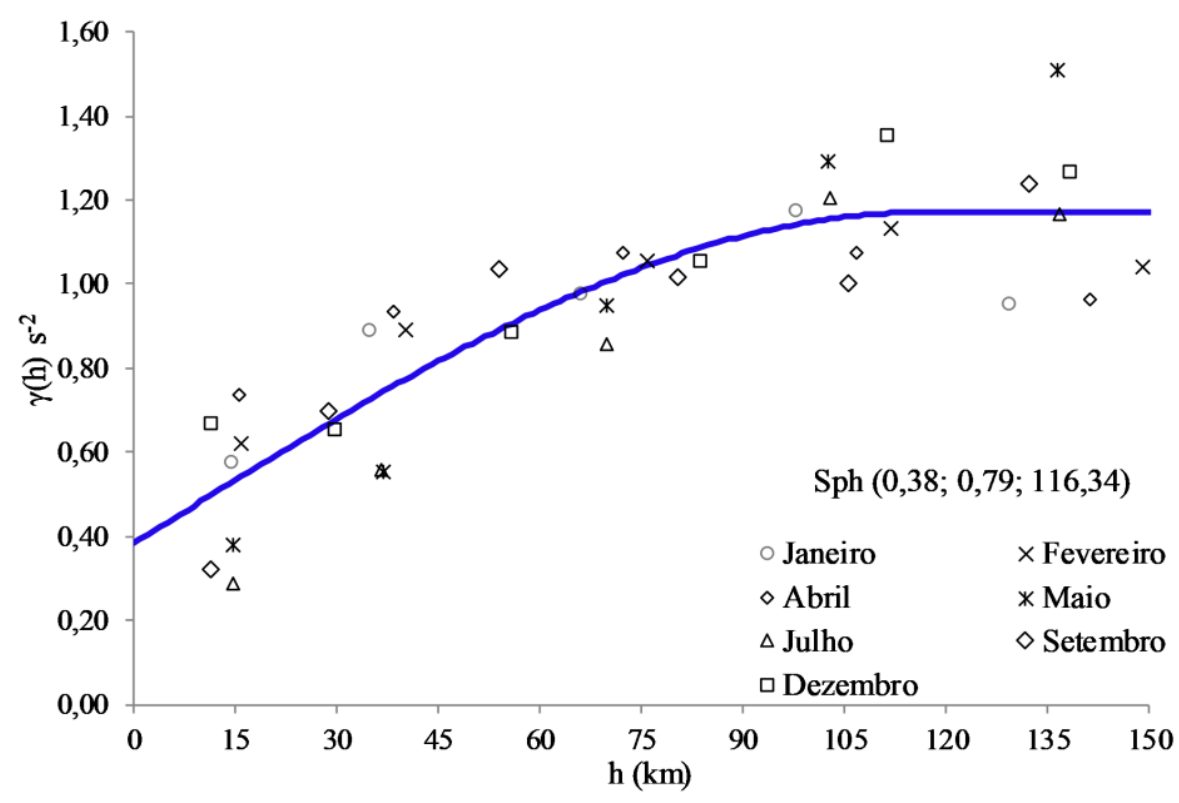

Figura 4. Semivariograma escalonado para os valores de precipitação prováveis $(\mathrm{P} \geq 75 \%)$ nos meses que apresentaram continuidade espacial. 
Os valores do modelo esférico $(0,38$; 0,79 e 116,34) apresentados na Figura 4, respectivamente, representam o efeito pepita (C0), a contribuição (C) e o alcance (A). A relação $\mathrm{C} /(\mathrm{C} 0+\mathrm{C})$ apresentou um valor igual a 0,67, indicando uma moderada estrutura espacial (CAMBARDELLA et al., 1994). De acordo com essa relação, $33 \%$ da estrutura de dependência espacial não pode ser explicada pela função de semivariância, $o$ fato, provavelmente, é decorrente da falta de posições amostrais com distâncias de separação inferior ao adotado no presente trabalho. Com base no valor de alcance $(116,34 \mathrm{~km})$ pode-se concluir que os dados de precipitação fornecidos por uma estação meteorológica, situada no domínio do presente trabalho, podem ser utilizados para inferir essa variável em torno de um raio de $116 \mathrm{~km}$.

Os mapas de precipitação provável $(\mathrm{P}$ $\geq 75 \%$ ) para a região noroeste do estado do Paraná são apresentados na Figura 5.

Observa-se que, nos meses relativos a cada estação do ano (primavera, verão, outono e inverno), há uma semelhança nos valores de precipitação provável. Souza (2006) explica que, no Paraná esse fato ocorre devido a predominância de massa de ar quente e úmida na estação de verão (dezembro, janeiro e fevereiro) que provoca um aumento na distribuição de chuvas, enquanto que, no outono (março, abril e maio), ocorre uma fase de transição, sendo, essas massas menos atuantes, apresentando maior influência das massas polares, que gradativamente, começam atuar com maior força no inverno (junho, julho e agosto), causando diminuição acentuada da precipitação. $\mathrm{O}$ autor menciona também, que na primavera (setembro, outubro e novembro) ocorre uma nova fase de transição, com as massas de ar quente e úmida voltando a atuar.

De acordo com a Figura 5, na estação correspondente à primavera, o comportamento espacial da precipitação apresenta uma distribuição mais homogênea no mês de setembro, porém, nos meses de outubro e novembro, meses o qual a precipitação aumenta cerca de $20 \mathrm{~mm}$ em relação ao mês de setembro, a distribuição apresenta maior volume na microrregião de Umuarama, tendo um decréscimo nesse volume em relação a microrregião de Paranavaí. Na estação de verão, os meses apresentam comportamento espacial da precipitação provável similares, com precipitações elevadas sobre todo o domínio e com valores compreendidos entre 70 a $134 \mathrm{~mm}$, porém, nota-se que a concentração de chuva aumenta do oeste para o leste.

Para os meses referentes ao outono, as precipitações variam entre 36 e $82 \mathrm{~mm}$ apresentando regiões isoladas de maior e menor valores, porém, nota-se que há uma maior concentração pluviométrica na microrregião de Cianorte nos meses de março e abril, que se estende para a microrregião de Umuarama no mês de maio.

Com relação aos meses de junho, julho e agosto (estação de inverno) são os que possuem menores valores de precipitação provável, respectivamente, com precipitação média esperada em torno de 35,24 e $15 \mathrm{~mm}$, variando de 7 a $57 \mathrm{~mm}$, sendo o mês de agosto o mais seco do ano (máxima de $27 \mathrm{~mm}$ ), denotando que a irrigação nessa região apresenta caráter suplementar (DANFÁ et al.,2011). 


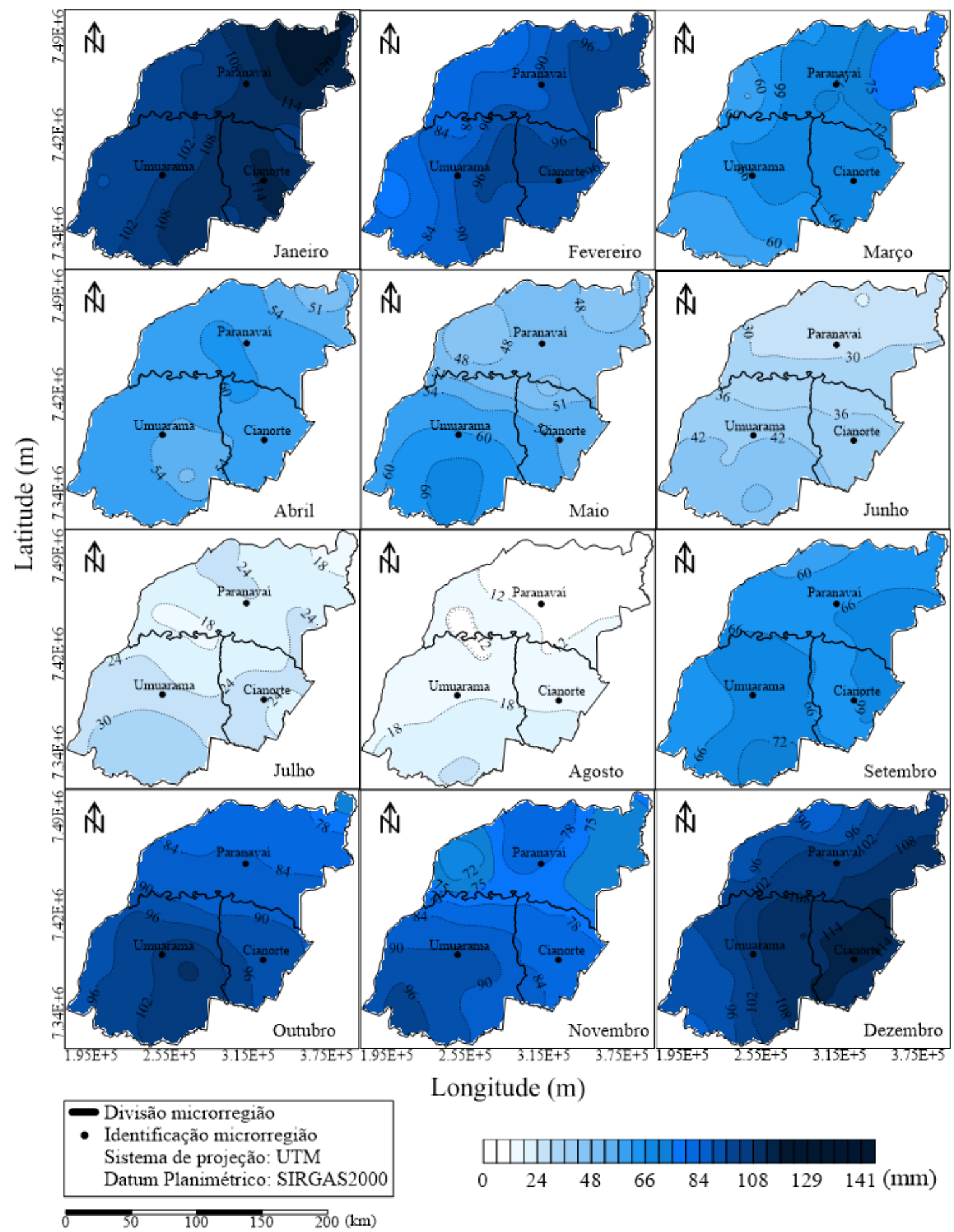

Figura 5. Mapas de precipitação provável mensal $(\mathrm{P} \geq 75 \%)$ para a região Noroeste do Paraná.

Segundo Santos et al. (2017), mesmo que o noroeste de Paraná possua a menor incidência de precipitação do estado, o mesmo não apresenta risco de déficit hídrico. Todavia, essa possibilidade deve ser assumida, principalmente, para culturas anuais ou que apresentem importância socioeconômica para a região, tais como: café, laranja, cana-de- açúcar, pastagens, soja, feijão e abacaxi (ANTONIEL et al., 2016; GOMES et al., 2012).

$\mathrm{Na}$ Figura 6 são apresentados os valores da média do desvio relativo (DRM) para cada posição amostral considerando os 12 meses avaliados. A posição que apresentou o menor valor de DRM foi a estação localizada 
no município de Tapejara, com valor de $0,57 \%$ e desvio padrão de 8,89. Conforme Vachaud et al. (1985), os baixos valores de DRM e do desvio padrão corroboram a estabilidade temporal desta localidade, portanto, a estação meteorológica de Tapejara pode ser adotada para representar a condição média da precipitação provável $(\mathrm{P} \geq 75 \%)$ no noroeste do Paraná, qualquer que seja o período. As posições localizadas nos municípios de
Querência do Norte e Alto Piquiri apresentaram os maiores valores, em módulo, da DRM. Conforme os dados analisados, a localidade representativa da estação meteorológica de Tapejara apresentou precipitação média mensal de $122,9 \mathrm{~mm}$, sendo dezembro (163 mm) e janeiro (166 $\mathrm{mm}$ ) os meses mais chuvosos e o mês de agosto apresentaram a menor média pluviométrica $(57 \mathrm{~mm})$.

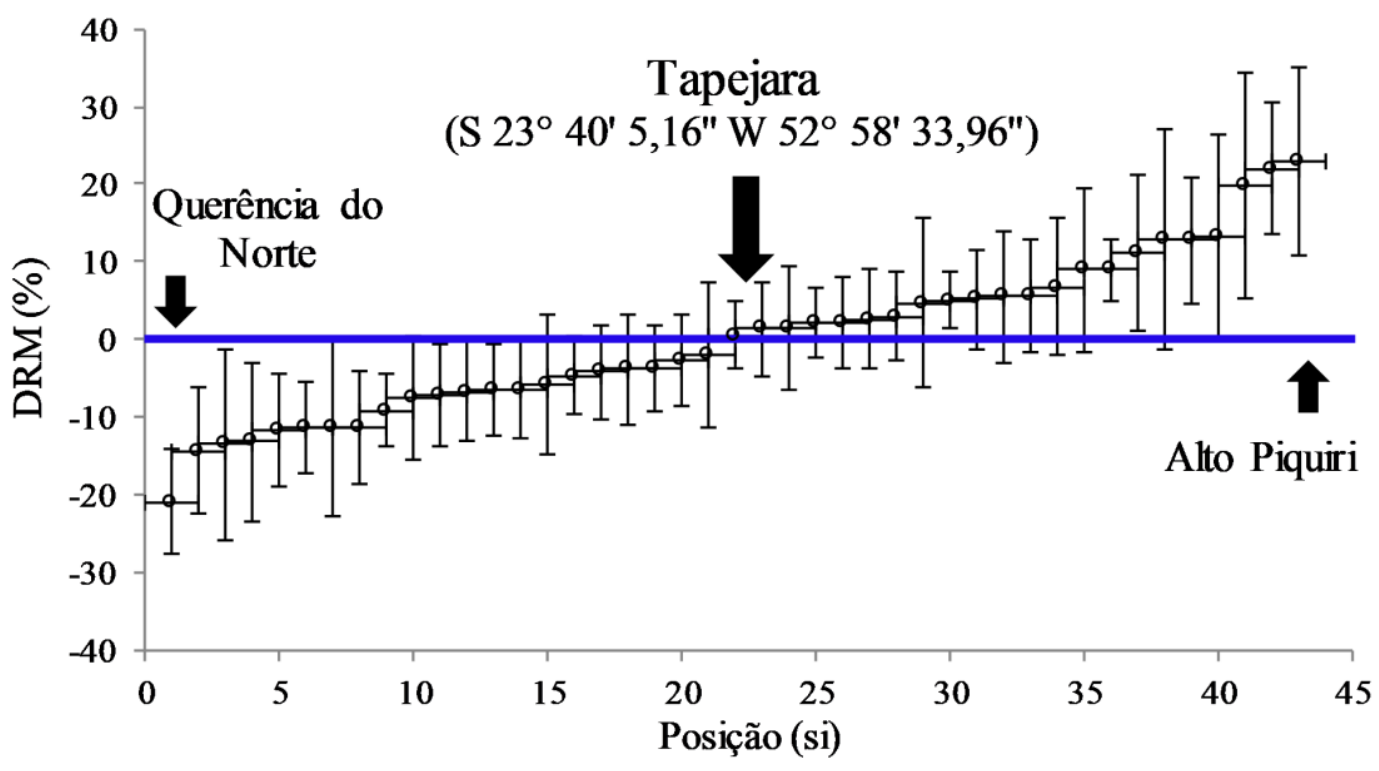

Figura 6. Diferença relativa média (DRM) e desvio padrão da variável ( $\mathrm{P} \geq 75 \%)$ em função da posição (si).

\section{CONCLUSÕES}

Com base nos resultados obtidos conclui-se que: i) a precipitação provável apresentou estrutura de dependência espacial, com alcance de $116 \mathrm{~km}$; ii) os mapas possibilitaram observar o comportamento da precipitação provável mensal, bem como caracterizar os meses que apresentam chuvas bem distribuídas sobre o domínio (setembro a março) e os meses mais secos (correspondentes ao inverno) e; iii) a estação localizada na cidade de Tapejara pode ser utilizada para previsão da condição média da precipitação provável.

\section{REFERÊNCIAS}

ALMEIDA, A. Q.; RIBEIRO, A.; PAIVA, Y.
G.; RASCON, N. Jr. L.; LIMA, E. P. Geoestatística no estudo de modelagem temporal da precipitação. Revista Brasileira de Engenharia Agrícola e Ambiental, v.15, n.4,

p.354-358, 2011. http//doi: 10.1590/S141543662011000400004

ANA - Agência Nacional das Águas. Hidroweb: Sistemas de informações hidrológicas. Disponível em: <http://hidroweb.ana.gov.br>. Acesso em: 27 de Agosto de 2018.

ANDRADE, A. R. S.; GODOY NETO, A. H.; CRUZ, A. F. S.; ANDRADE, E. K. P.; SANTOS, V. F.; SILVA, T. N. P. Geoestatística aplicada à variabilidade espacial e padrões nas séries temporais da precipitação no Agreste Pernambucano. 
Journal of Environmental Analysis and Progress, v.3, n.1, p.126-145, 2018. http//doi: 10.24221/jeap.3.1.2018.1668.126-145

ANTONIEL, L. S.; PRADO, G.; TINOS, A. C.; BELTRAME, G. A.; ALMEIDA, J. V.; CUCO, G. P. Pasture production under different irrigation depths. Revista Brasileira de Engenharia Agrícola e Ambiental, v.20, n.6, p.539-544, 2016. http://dx.doi.org/10.1590/1807-

1929/agriambi.v20n6p539-544

ARAÚJO, W. F.; ANDRADE JUNIOR, A. S.; MEDEIROS, R. D.; SAMPAIO, R. A. Precipitação pluviométrica mensal provável em Boa Vista, Estado de Roraima, Brasil. Revista Brasileira de Engenharia Agrícola e Ambiental, v.5, n.3, p.563-567, 2001. http//doi: $\quad 10.1590 / S 1415-$ 43662001000300032

BAÚ, A. L.; GOMES, B. M.; QUEIROZ, M. M. F.; OPAZO, M. A. U.; SAMPAIO, S. C. Comportamento espacial da precipitação pluvial mensal provável da mesorregião Oeste do estado do Paraná. Irriga, v.11, n.2, p.150168, $2006 . \quad \mathrm{http} / /$ doi: 10.15809/irriga.2006v11n2p150-168

BERNARDO, S.; SOARES, A. A.; MANTOVANI, E. C. Manual de Irrigação. 8. ed. Viçosa: UFV, 2006. 625 p.

CAMBARDELLA, C. A.; MOORMAN, T. B.; NOVAK, J. M.; PARKIN, T. B.; KARLEN, D. L.; TURCO, R. F.; KONOPKA, A. E. Field-scale variability of soil properties in Central Iowa Soils. Soil Science Society of America Journal, v.58, n.5, p. 1501-1511, 1994. $\mathrm{http} / / \mathrm{doi}:$ 10.2136/sssaj1994.03615995005800050033x

COAN, B. P.; BACK, A. J.; BONETTI, A. V. Precipitação mensal e anual provável no estado de Santa Catarina. Revista Brasileira de Climatologia, v.15, n.10, p.122-142, 2014. http//doi: 10.5380/abclima.v15i0.38348

DANFÁ, S.; SILVA, A. M.; MELLO, C. R.; COELHO, G.; VIOLA, M. R.; ÁVILA, L. F.
Distribuição espacial de valores prováveis de precipitação pluvial para períodos quinzenais, em Guiné-Bissau. Revista Brasileira de Engenharia Agrícola e Ambiental, v.15, n.1, p.67-74, 2011. http//doi: 10.1590/S141543662011000100010

FRAZIER, A. G.; GIAMBELLUCA, T. W.; DIAZ, H. F.; NEEDHAM, H. L. Comparison of geostatistical approaches to spatially interpolate month-year rainfall for the Hawaiian Islands. International Journal of Climatology, v.36, n.3, p.1459-1470, 2016. https://doi.org/10.1002/joc.4437

FREITAS, A. J. et al. Equações de chuvas intensas no Estado de Minas Gerais. Belo Horizonte: UFV, 2001. 65p.

FRITZSONS, E.; MANTOVANI, L. E.; WREGE, M. S.; CHAVES NETO, A. Análise da pluviometria para definição de zonas homogêneas no estado do Paraná. Raega - O Espaço Geográfico em Análise, v. 23, p. 555-572, 2011.

GOMES, E. P.; BISCARO, G. A.; ÁVILA, M. R.; LOOSLI, F. S.; VIEIRA, C. V.; BARBOSA, A. P. Desempenho agronômico do feijoeiro comum de terceira safra sob irrigação na região Noroeste do Paraná. Semina: Ciências Agrárias, v.33, n.3, p.899910, 2012. http//doi:10.5433/16790359.2012v33n3p899

GONÇALVES, A. C. A.; TRINTINALHA, M. A.; FOLEGATTI, M. V.; REZENDE, R.;TORMENA, C. A. Spatial variability and temporal stability of water storage in a cultivated tropical soil. Bragantia, v. 69, n.3, p. 153-162, 2010. http//doi: 10.1590/S000687052010000500016

GONÇALVES, A. C. A.; FOLEGATTI, M. V.; SILVA, A.P. Estabilidade temporal da distribuição espacial da umidade do solo em área irrigada por pivô central. Revista Brasileira de Ciência do Solo, v. 23, n.1, p. 155-164, 1999. http//doi: 10.1590/S010006831999000100019 
JAVARI, M. Geoestatistical modeling to simulate daily rainfall variability in Iran. Cogent Geoscience, v.3, p.1-29, 2017. https://doi.org/10.1080/23312041.2017.14168 77

LIMA, J. S. S.; SILVA, S. A.; BERNARDES, P. M.; FONSECA, A. S.; PEREIRA, J. M. S. Variabilidade espacial dos percentis 75 da precipitação pluvial mensal no estado do Espírito Santo. Engenharia na Agricultura, v.24, n.5, p.291-296, 2016. http//doi: 10.13083/reveng.v24i5.700

LONGO, A. J.; SAMPAIO, S. C.; SUSZEK, M. Modelo Computacional para estimativa das precipitações prováveis utilizando as distribuições de probabilidades gama e lognormal. Revista Varia Scientia, v.6, n.11, p.141-148, 2006.

MELLO, C. R.; VIOLA, M. R.; CURI, N.; SILVA, A. M. Distribuição espacial da precipitação e da erosividade da chuva mensal e anual no estado do Espírito Santo. Revista Brasileira de Ciência do Solo, v.36, n.6, p.1878-1891, 2012. http//doi: 10.1590/S010006832012000600022

PASSOS, M. L. V.; MENDES, T. J. Precipitação pluviométrica mensal e anual provável para o município de Turiaçu-MA. Revista Brasileira de Agricultura Irrigada, v.12, n.1, p.2283-2292, 2018. http//doi: 10.7127/rbai.v12n100672

PASSOS, M. L. V.; RAPOSO, A. B.; MENDES, T. J. Estimativa da distribuição da precipitação pluviométrica provável em diferentes níveis de probabilidade de ocorrência. Revista Brasileira de Agricultura Irrigada, v.11, n.1, p.1106-1115, 2017. http//doi: 10.7127/rbai.v11n100498

SANTIAGO, E. J. P.; OLIVEIRA, G. M.; LEITÃO, M. M. V. B. R.; MOURA, M. S. B.; GONÇALVES, I. S. Precipitação esperada, em diferentes níveis de probabilidade, na região de Juazeiro-BA. Journal of Environmental Analysis and Progress, v.2, n.4, p.457-464, 2017. http//doi: 10.24221/jeap.2.4.2017.1462.457-464

SANTOS, L. C.; JOSÉ, J. V.; ALVES, D. S.; NITSCHE, P. R.; REIS, E. F.; BENDER, F. D. Space-time variability of evapotranspiration and precipitation in the State of Paraná, Brazil. Revista Ambiente \& Água, v.12, n.05, p.743-759, 2017. http//doi: 10.4136/ambi-agua.2057

\begin{tabular}{lccr} 
SOUZA, & P. & Estudo & da \\
variabilidade da & \multicolumn{2}{c}{ precipitação } & no \\
estado do Paraná & \multicolumn{2}{c}{ associado à } \\
anomalia & da TSM & \multicolumn{2}{c}{ no oceano } \\
pacífico. & 2006. & 84 & f. Dissertação \\
(Mestrado em Geografia) & - Universidade \\
Estadual de Maringá. &
\end{tabular}

TUCCI, C. E. M.; SILVEIRA, A. L. L. Hidrologia: ciência e aplicação. 4. ed. Porto Alegre: ABRH, 2009. 943p.

VACHAUD, G.; PASSERAT DE SILANS, A.; BALABANIS, P. \& VAUCLIN, M. Temporal stability of spatially measured soil water probability density function. Soil Science Society of America Journal, v.49, n.4, p.822-828, 1985 . http//doi: 10.2136/sssaj1985.03615995004900040006x

VIEIRA, S. R.; LOMBARDI NETO, F.; BURROWS, I. T. Mapeamento das chuvas máximas prováveis para o Estado de São Paulo. Revista Brasileira de Ciência do Solo, v. 15 p. 219-224, 1991

VILLELA, S. M.; MATTOS, A. Hidrologia aplicada. São Paulo: McGraw Hill do Brasil, 1975. 245p.

WANDERLEY, H. S.; AMORIM, R. F. C.; CARVALHO, F. O. Interpolação espacial da precipitação no Estado de Alagoas utilizando técnicas geoestatísticas. Campo Digital, v.8, n.1, p.34-42, 2013. http//doi: 10.17648/ambientale.v2i2.105 